Article

\title{
Detection of novel biomarkers in saliva of rheumatoid arthritis model mice by proteomics and pathological analysis
}

\author{
Wakako Sakaguchi ${ }^{1}$, Juri Saruta ${ }^{2, *}$, Shinya Fuchida ${ }^{2}$, Yuko Yamamoto ${ }^{3}$, Masahiro To ${ }^{4}$, Tomoko Shimizu ${ }^{5}$, \\ Mayumi Yakeishi ${ }^{1}$ and Keiichi Tsukinoki ${ }^{1}$
}

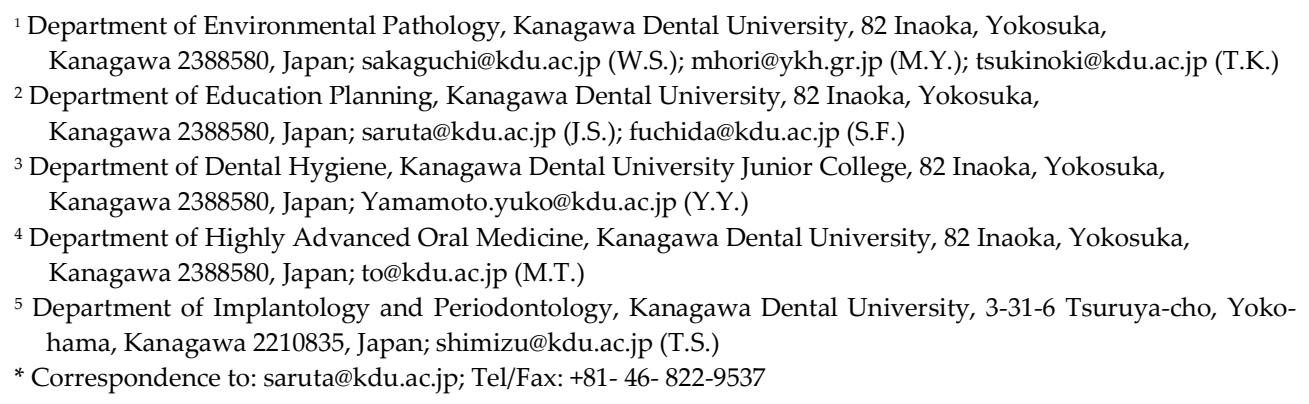

\begin{abstract}
Rheumatoid arthritis (RA) is an autoimmune disease in which joints are gradually destroyed, and early diagnosis and treatment before joint deformation or destruction is important. The detection of novel RA biomarkers in saliva may facilitate the early detection of RA before the onset of disease. In this study, we conducted a comprehensive proteomic analysis of salivary proteins from RA model mice. Proteins were identified by Western blotting and enzyme-linked immunosorbent assay in serum, saliva, and ankle joints from DBA/1JJmsSlc mice, a model of rheumatoid arthritis. Ankle joints and submandibular glands were hematoxylin and eosin stained and immunostained, and the results were compared with those of control mice. Citrullinated $\alpha 1$ antitrypsin (A1AT, 46 $\mathrm{kDa}$ ) was commonly detected in saliva, serum, and ankle joints of severe RA model mice, and was confirmed by proteome analysis. Western blotting detected a band corresponding to $46 \mathrm{kDa}$ in serum, saliva and ankle joints, and immunostaining of ankle joints with A1AT antibody showed a strong positive signal in the synovium. In DBA/1JJmsSlc mice, not only cyclic citrullinated peptide antibodies but also A1AT may be involved in protein citrullination and contribute to the development and severity of RA.
\end{abstract}

Keywords: anti-citrullinated protein antibody (ACPA), alpha-1-antitrypsin (A1AT), DBA/1JJmsSlc mice Proteome analysis, rheumatoid arthritis (RA)

\section{Introduction}

Rheumatoid arthritis (RA) is an autoimmune disease that affects about $1 \%$ of the world's population, causing progressive bone and joint destruction [1,2]. The aetiology of this disease remains unknown, but it is believed to be due to genetic, environmental, or immune factors. Other factors such as smoking [3,4], stress [5,6], periodontal disease [7,8], and gut flora $[9,10]$ are also known to be involved in the onset and exacerbation of the disease. Seventy percent of RA cases result in joint destruction within 2 years after onset, thus, it is important to diagnose and treat it early. However, early diagnosis is often difficult due 
to the different clinical symptoms of RA. The development of disease-modifying antirheumatic drugs (DMARDs), such as synthetic and biological DMARDs used to target inflammation and thereby prevent further joint damage, has made RA a manageable disease. DMARDs have repeatedly shown the potential to significantly improve disease symptoms and prevent disease progression in RA patients, but with significant side effects and high economic costs [11,12]. In addition, the underlying diagnosis remains unresolved.

Anti-citrullinated protein antibodies (ACPA) are autoantibodies to citrullinated proteins that react with many types of protein antigens, including type II collagen, fibrin products, vimentin, and histones [13-15]. Citrullinated proteins are usually not detected in normal joints of ACPA-positive individuals, and when citrullinated proteins appear in joints, they trigger an antigen-antibody reaction that produces a variety of cytokines such as IL-6 and IL-17 [16,17]. ACPA is detectable years before the onset of symptoms and its levels increase with the onset of symptoms. In addition, various isotypes can be observed during the onset of symptoms. This suggests that various events occur before the onset of RA and that autoantibodies are expressed in predisposed individuals. Therefore, the presence of these autoantibodies may help predict the onset of RA, and the identification of citrullinated proteins may be important for the early diagnosis of RA.

The clinical application of saliva is based on its advantages such as ease of collection, painlessness, and non-coagulability. Saliva has biological information comparable to blood and urine, and saliva contains a wealth of readily available information in the form of biomarkers, which have been clinically applied to cancer [18,19], Alzheimer's disease [20], and stress [21]. In addition, it has been found to be highly sensitive in detecting salivary autoantibodies in Sjögren 's syndrome and Behcet's disease [22], and IgG antibodies against HIV-1 in HIV patients [23,24].

In this study, DBA / 1JJmsSlc was used. In this mouse model, arthritis and chronic inflammation, such as the severe joint swelling and periostitis seen in rheumatoid arthritis, is induced by administration of bovine type II collagen. We previously reported that infection of DBA mice with Porphyromonas gingivalis ( $P$. gingivalis) aggravated arthritis, and anti-CCP antibodies were detected in the saliva of the mice [25]. Animal models of arthritis have been used to identify key molecules involved in the pathological mechanisms underlying RA and to discover new drug candidates for RA, and the DBA mouse model has been established as the most standard arthritis model. [26,27]. Proteome analysis is currently used to study biomarkers for various diseases such as cancer and autoimmune diseases, leading to early detection of these diseases [28-31]. In this paper, we report a proteomic analysis of the expression of proteins related to citrullination in saliva using DBA mice in a comprehensive manner.

\section{Results}

\subsection{Progression of inflammation}

The ankle joints in the severe RA group was clearly redder and more swollen compared to that in the control group. Micro computerised tomography (Micro CT) images showed thinner leg bone and periarticular joint destruction in the severe RA group compared to the control group (Figure $1 \mathrm{a}, \mathrm{b}$ ). Haematoxylin and eosin (HE) staining of the ankle joints showed more inflammatory cells in the severe RA group. Notably, chronic inflammatory cells were found around the ankle joints, indicating bone destruction (Figure $2 b, d$ ). These findings were not observed in those of the control group (Figure $2 a, c)$. Joint deformity was also observed in the severe RA group. The arthritis scores of the ankle joints of the mice $(0,4.01 \pm 0.25$, and $9.17 \pm 1.94$ in the control, mild, and severe RA groups, respectively) (Figure 3 ) differed significantly $(n=5, p<0.05)$ 

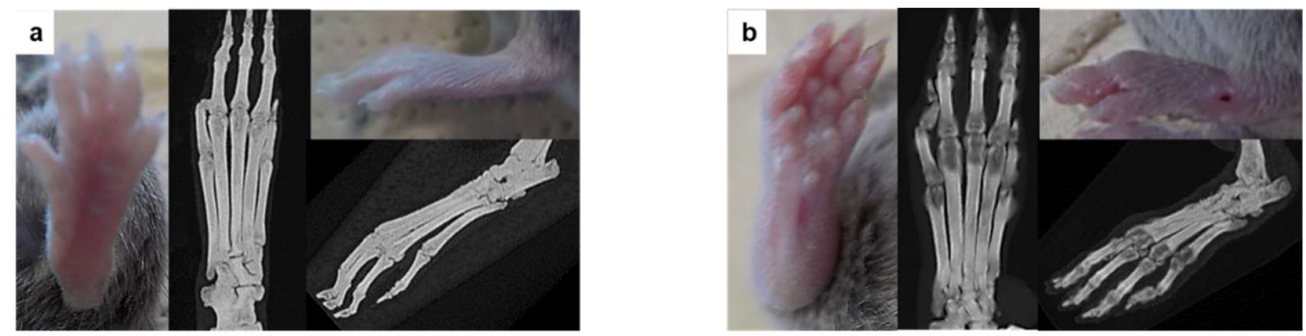

Figure 1. In the severe rheumatoid arthritis (RA) group, swelling of the ankle joint is more pronounced macroscopically than in the control group (a), (b). Micro computerised tomography (CT) images show the thinning of the tarsal bones of the legs and deformities of the joints in the severe RA (a), (b). (a): Control, (b): severe RA.

\section{Low magnification}
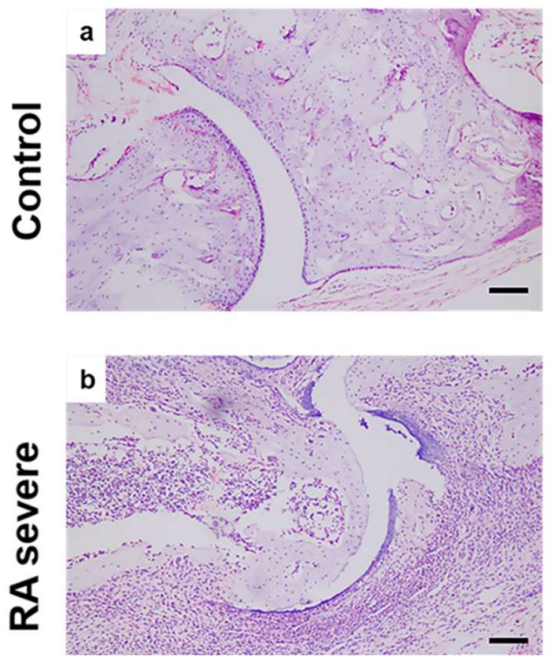

High magnification
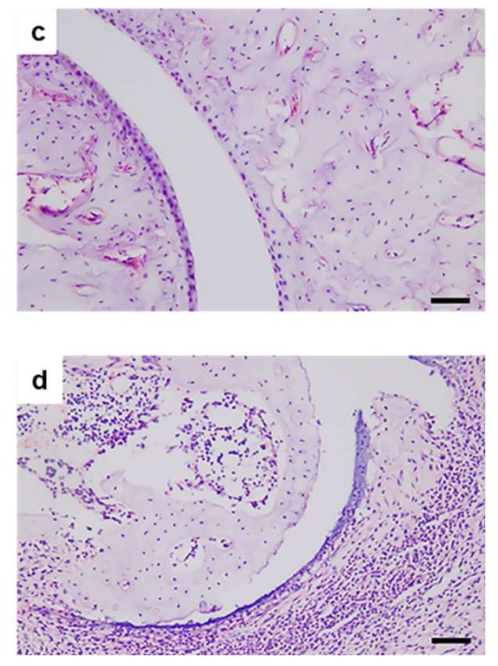

Figure 2. Haematoxylin and eosin (HE) staining of the ankle joints shows marked joint destruction and inflammatory cell infiltration in the severe rheumatoid arthritis (RA) group (b) (d). These were not observed in the control group (a) (c). (a) (c): Control, (b) (d): Severe RA. (a) (b): Low magnification, scale bar $=100 \mu \mathrm{m}$, (c) (d): High magnification, scale bar $=100 \mu \mathrm{m}$.

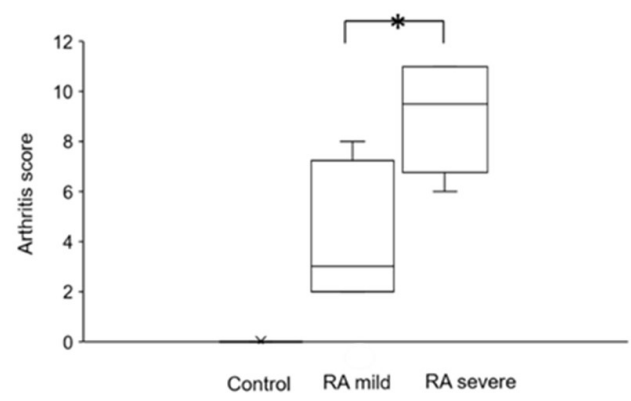

Figure 3. The arthritis scores from each group are shown. The control group had no swelling, and their score was 0 . The score of the severe RA group was significantly higher than that of the mild RA group ( ${ }^{*}$ Welch's t test, $\left.n=5, p<0.05\right)$. 
A database search (Mascot search) of gel fragments obtained by protease treatment identified various citrullinated proteins. They were identified from $55 \mathrm{kDa}$ gel fragments of serum, ankle joints, and saliva of mice in the severe RA group (Fig. 4). Citrullinated $\alpha$ 1-antitrypsin (A1AT) was commonly identified in serum, saliva, and ankle joints of mice in the severe RA group, and $46 \mathrm{kDa}$ gel fragments of these sites were also analyzed and found to be citrullinated (Fig. 5). 


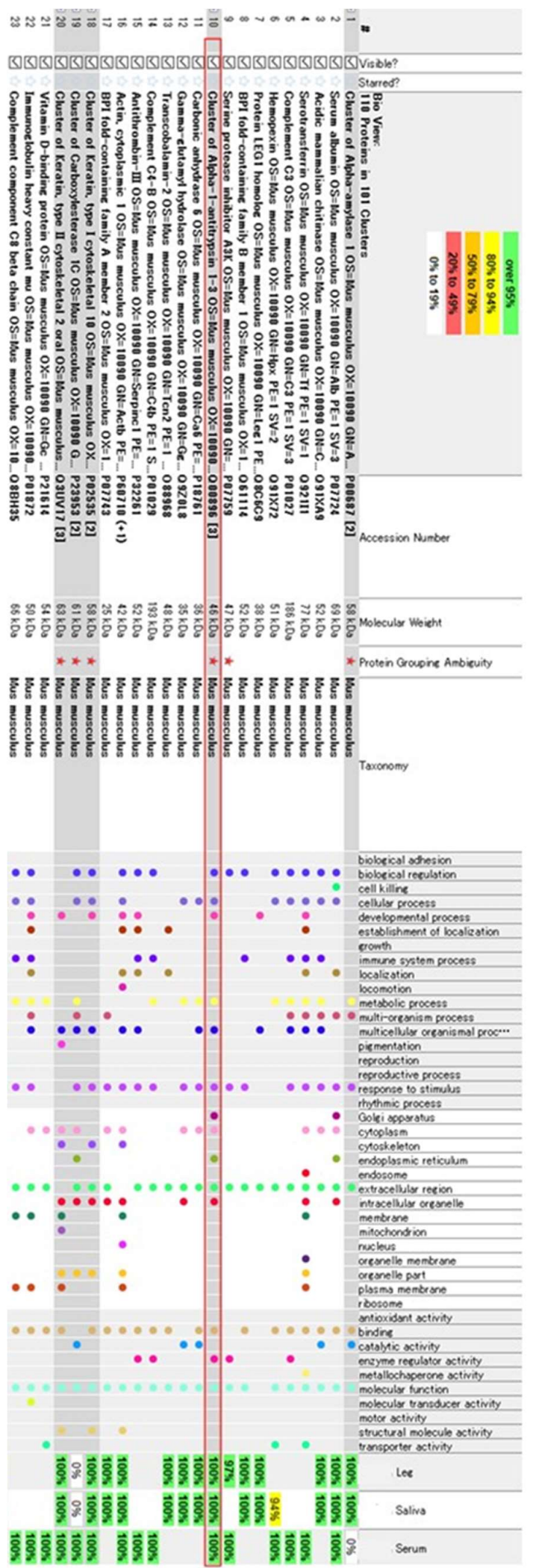

Figure 4. Proteome analysis showed that citrullination was observed in a variety of proteins. Among them, A1AT, which is citrullinated by deimidation of arginine residues, was found to be citrullinated to arginine in the ankle joints (Foot), serum, and saliva of the severe RA group (red boxed area). 
Q00896 (100\%), 45,824.4 Da

Alpha-1-antitrypsin 13 OS=Mus musculus $O X=10090 \mathrm{GN}=S$ erpina1c $P E=1 \mathrm{SV}=2$

0 exclusive unique peptides, 0 exclusive unique spectra, 9 total spectra, 88/412 amino acids (21\% coverage)
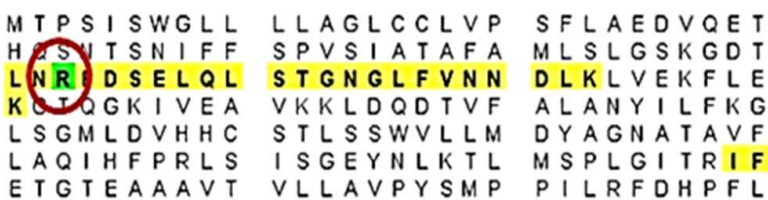

DTSQKDQSPA SHEI ATNLGD HTQILEGLQF NLTQTSEADI

EAKNHYQAEV

KWKKPFOPEN

F S N F A ESEE

LLPDDGKMQH LEQTLSKELI

N NGADLSGIT EENAPLKLSQ

E T G T E A

$\checkmark L L A \vee P Y$

PILRFDHPFL FI I FEEHTQS PLFVGKVVDP

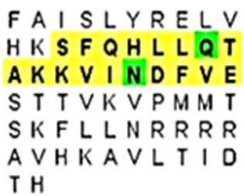

$\mathrm{TH}$

Figure 5: Citrullination sites in a mouse model of severe RA. Asparagine $(\mathrm{N})$, glutamine $(\mathrm{Q})$, arginine $(\mathrm{R})$, N-terminal phenylalanine (F). Composition is $\mathrm{H}(-1), \mathrm{N}(-1), \mathrm{O}(+1)$ ( $\mathrm{R}$ indicates citrullination, red circle).

\subsection{Histological examination of the ankle joints}

Immunohistochemical staining was performed on serial sections of the ankle joints samples from the severe RA group that showed particularly intense HE staining of inflammatory cells. In the control group, immunostaining of A1AT and CCP showed no positive signal in or around the synovium (Figure $6 \mathrm{a}, \mathrm{b}$ ). Positive signals for A1AT and $\mathrm{CCP}$ antibodies were observed in the periarticular synovium in the severe RA group, and particularly strong signals were observed for A1AT (Figure $6 \mathrm{c}, \mathrm{d}, \mathrm{f}, \mathrm{g}$ ). The negative control group also showed no positive signal, demonstrating the specificity of this staining (Figure $5 \mathrm{e}, \mathrm{h}$ ).

HE staining of the submandibular gland showed no infiltration of inflammatory cells or morphological changes in the ducts or acinar cells in the severe RA group, and the morphology was the same as that in the control group (Figure $7 \mathrm{a}, \mathrm{b}$ ). In addition, immunostaining of the submandibular glands of the severe RA group did not show positive signals for A1AT or CCP antibodies (Figure $7 \mathrm{c}, \mathrm{d}$ ). 

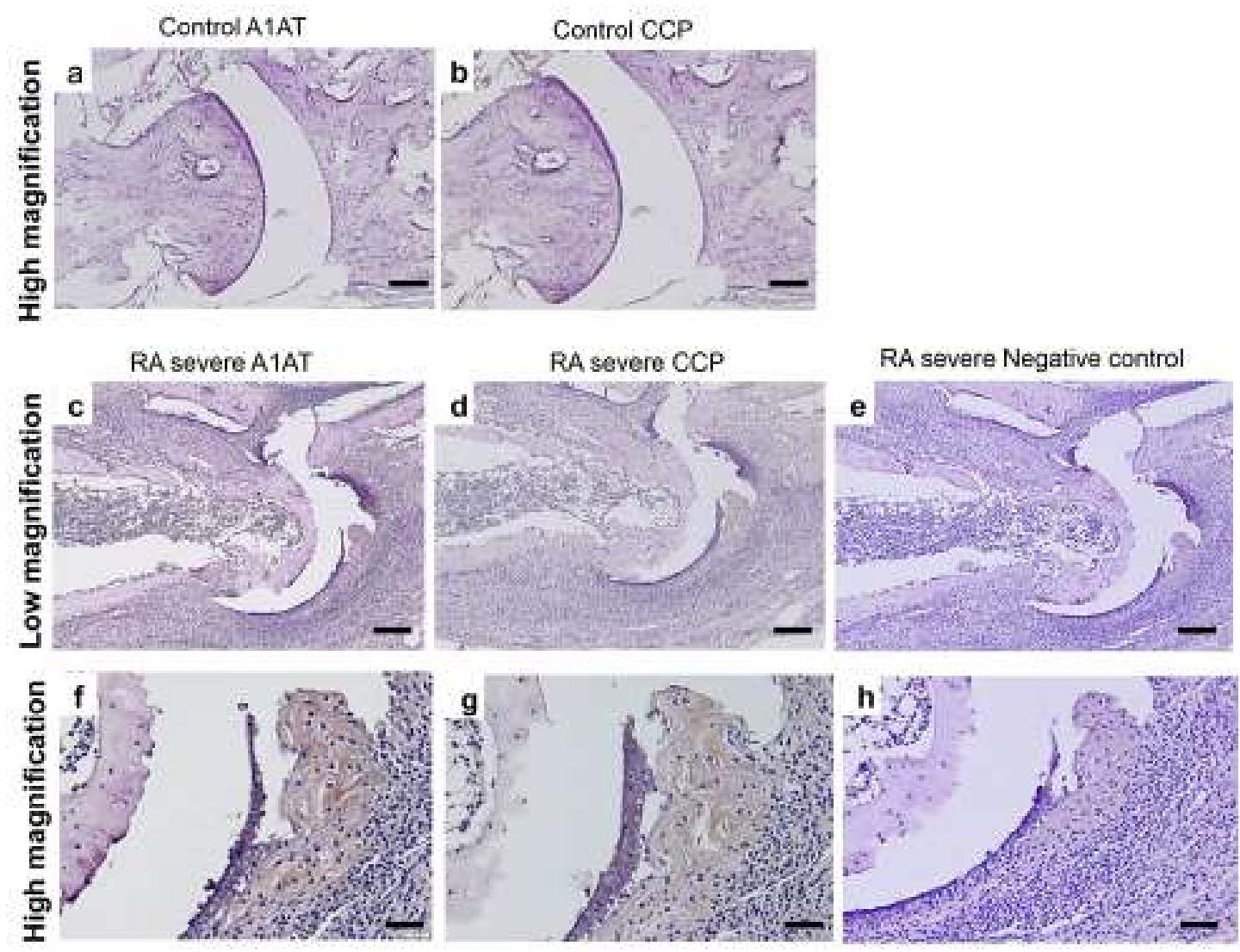

Figure 6. Ankle joints were immunostained with alpha-1-antitrypsin (A1AT) and anti-citrullinated peptide (CCP) antibodies. In the controls, neither A1AT nor anti-CCP antibodies show positive signals, while in the severe RA groups, both A1AT and anti-CCP antibodies show positive signals in the synovium, with A1AT showing even stronger signals. (a), (b): Control, high magnification, scale bar $=100 \mu \mathrm{m},(\mathrm{c}),(\mathrm{d}),(\mathrm{e})$ : Severe RA, low magnification, scale bar $=100 \mu \mathrm{m},(\mathrm{f}),(\mathrm{g}),(\mathrm{h})$ : Severe RA, high magnification, scale bar $=100 \mu \mathrm{m}$.
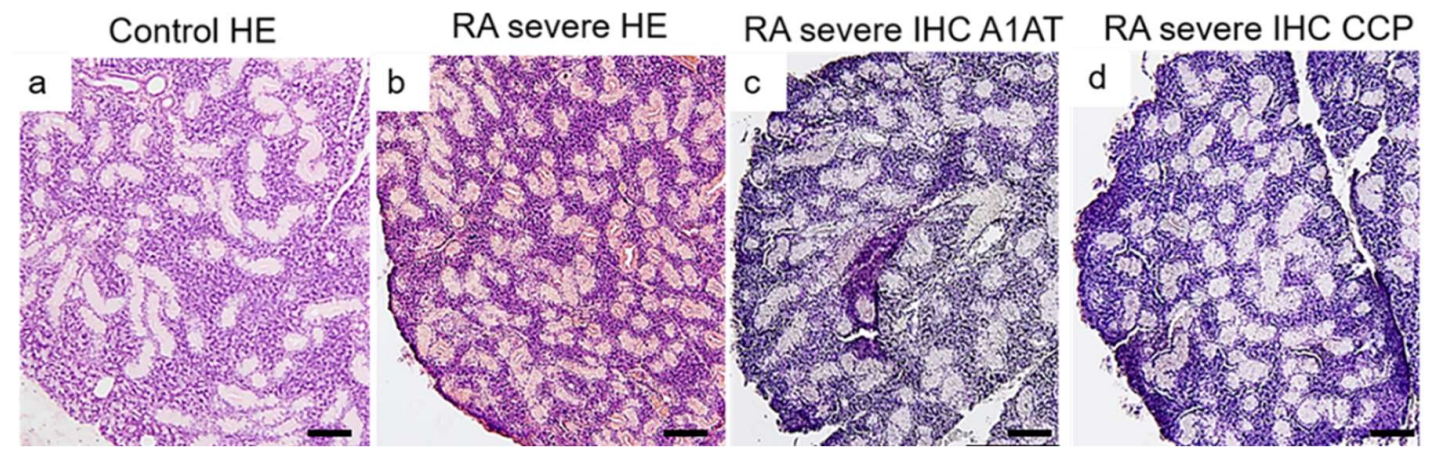

Figure 7. HE staining of mouse submandibular glands shows no change between the control and severe RA groups (a), (b). Immunostaining with alpha-1-antitrypsin (A1AT) and anti-citrullinated peptide (CCP) antibodies shows no positive signal in the submandibular glands of the severe RA group (c), (d). (a): Control, HE staining, scale bar $=100 \mu \mathrm{m}$, (b): Severe RA, HE staining, scale bar $=100 \mu \mathrm{m}$, (c): Severe RA, immunostaining with A1AT antibody, scale bar $=100 \mu \mathrm{m}$, (d): Severe RA, immunostaining with CCP antibody, scale bar $=100 \mu \mathrm{m}$ 


\subsection{Detection of CCP antibody}

The CCP antibody levels of the control, severe RA, and mild RA groups were compared using the enzyme-linked immunosorbent assay (ELISA) method. Comparisons showed a significant difference in serum levels between each comparison group (Figure 8 a). Since no CCP was detected in the saliva of the controls, the mild and severe RA groups were compared, and the severe RA group showed significantly higher levels (Figure $8 \mathrm{~b}$ ). A significant difference was observed in all ankle joint comparisons (Figure $8 \mathrm{c}$ ). These results show that CCP antibody levels in the serum, saliva, and ankle joints of the severe RA group were significantly higher than those in the other groups $(n=5$, $p<0.05)$.
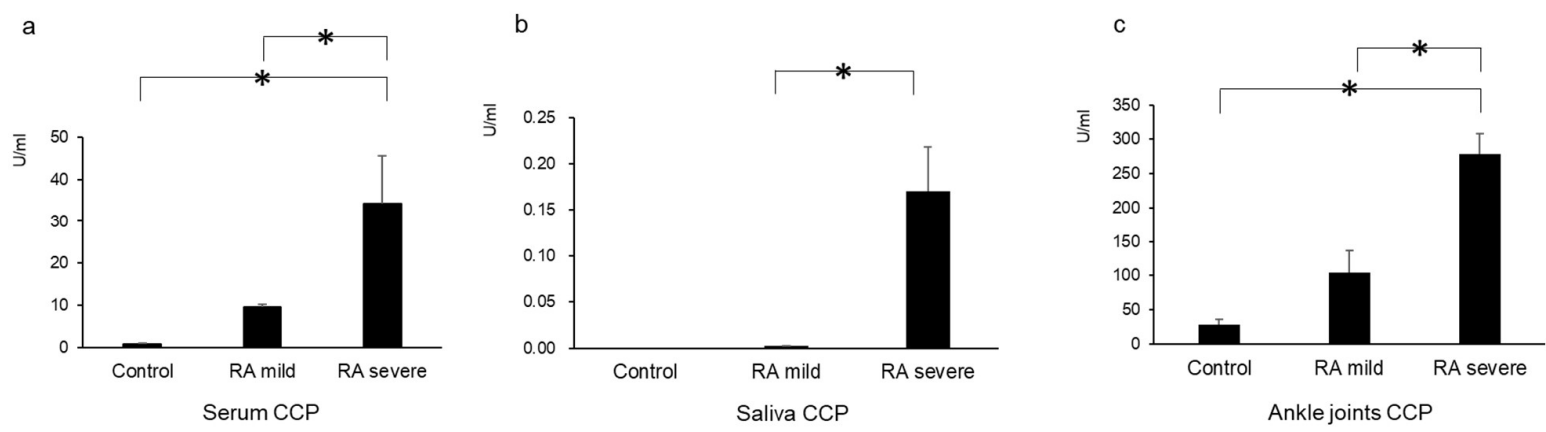

Figure 8. The amount of anti-citrullinated peptide (CCP) in the serum and ankle joints of the control and mild RA groups was significantly different from that in the severe RA group. The amount of CCP in the saliva was also significantly higher in the severe RA group than that in the mild group and was not detected in the control group. ( ${ }^{*}$ Post-hoc test using Bonferroni correction, a: $p<0.05$, b: $p<0.05$, c: $p<0.05, \mathrm{n}=5$ per group.) (a): Serum CCP, (b): Saliva CCP, and (c): Ankle joints CCP antibody levels.

\subsection{Western blot analysis}

Proteomic analysis identified a $46 \mathrm{kDa}$ citrullinated protein identified as A1AT and a $55 \mathrm{kDa}$ anti-CCP antibody. Similarly, western blotting revealed a $46 \mathrm{kDa}$ band in the serum, saliva, and ankle joint samples in both the severe and mild RA groups (Figure $9 \mathrm{a}, \mathrm{b}, \mathrm{c}$ ). When the intensity of the band was graphed using ImageJ software (version: ij153-win-java8; NIH, Bethesda, MD, USA), the severe RA group showed more intense bands than the mild RA group. In addition, bands appeared in both the severe and mild RA groups at $55 \mathrm{kDa}$ (Figure $9 \mathrm{~d}, \mathrm{e}, \mathrm{f}$ ), whereas more intense bands were observed in the severe RA group at $46 \mathrm{kDa}$ (Figure $9 \mathrm{a}, \mathrm{b}$, c). In the control group, bands also appeared at $46 \mathrm{kDa}$ in the ankle joints samples and at $55 \mathrm{kDa}$ in the serum, saliva, and ankle joints samples, but were the faintest of the three groups (Figure $8 \mathrm{c}, \mathrm{d}, \mathrm{e}, \mathrm{f}$ ). 
a

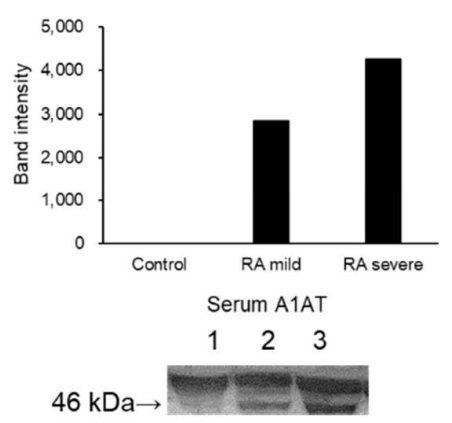

d

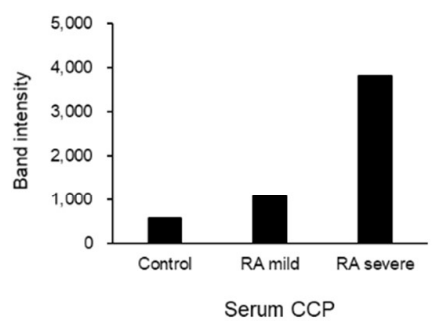

$55 \mathrm{kDa} \rightarrow$ b
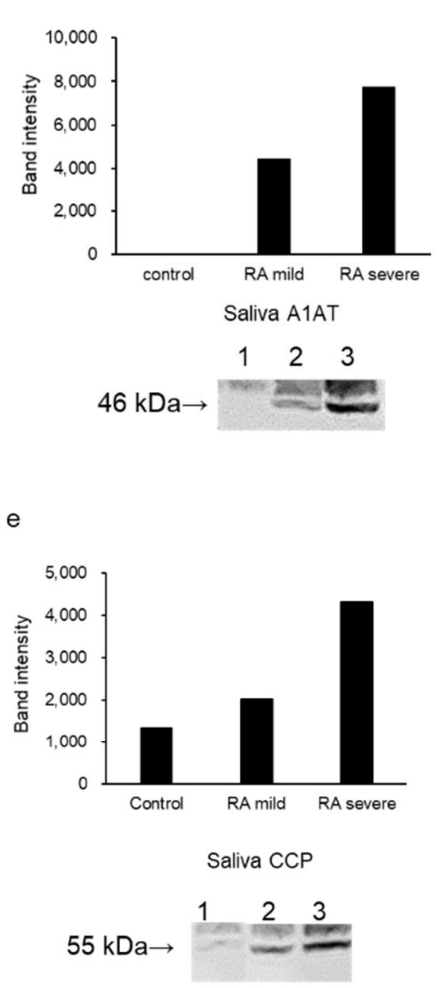

c

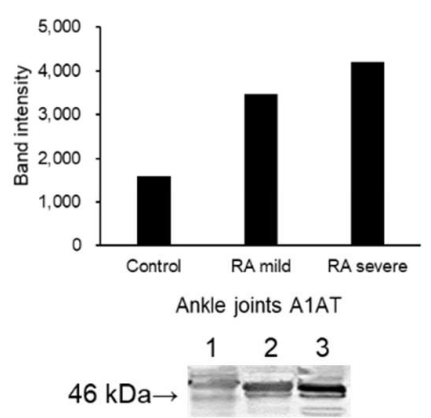

f

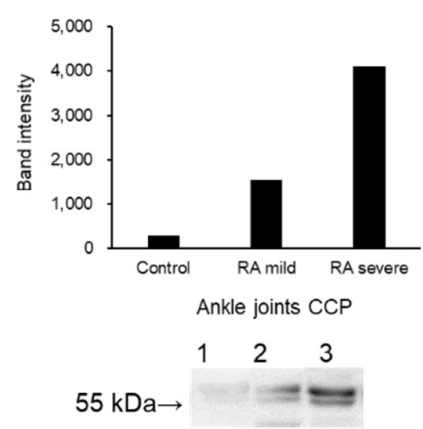

Figure 9. Western blotting results show that alpha-1-antitrypsin (A1AT, $46 \mathrm{kDa}$ ) was detected in the serum, saliva, and ankle joints. When the band intensity was quantified using ImageJ, the severe RA group was determined to have the highest expression levels in their serum, saliva, and ankle joints. Furthermore, results show that CCP (55 kDa) was detected in the serum, saliva, and ankle joints. Lane 1: Control; Lane 2: mild RA; Lane 3: severe RA. (a), (d): Serum band intensity; (b), (e): Saliva band intensity; (c), (d): Ankle joints band intensity.

\section{Discussion}

In addition to the autoantibody system that recognizes citrullinated proteins such as ACPA, autoantibody system against carbamylated proteins (anti-CarP) are known to exist in the serum of RA patients. In addition, Verheul et al. analysed the molecular structure of Ca-FCS protein recognized by anti-CarP antibodies and found that carbamylated $\alpha-1$ antitrypsin (Ca-A1AT) is a potential antigenic target of anti-CarP antibodies in RA patients [32]. This study, we showed that joint inflammation increases the amount of citrullinated A1AT in synovium in a mouse model of rheumatoid arthritis, suggesting that citrullinated A1AT may be involved in the pathogenesis of RA. A1AT, a serine protease inhibitor, is a glycoprotein produced mainly in hepatocytes, and is said to increase more than 4-fold during an acute inflammatory reaction. A1AT levels are also increased in chronic hepatitis, cirrhosis, diabetic malignancies, and neoplastic malignancies (especially leukemia and hepatocellular carcinoma). A1AT deficiency causes inflammatory diseases such as hereditary cirrhosis, juvenile cirrhosis, obstructive lung disease, and systemic vasculitis $[33,34]$. Recent studies have confirmed that A1AT is a highly abundant serum protease inhibitor that strongly limits the protease-mediated entry of SARS-CoV-2 [35,36]. In this study, several citrullinated proteins were detected by proteomic analysis (Supplementary Table 1), and citrullinated A1AT was detected in serum and saliva, and ankle joints. Immunohistochemical staining of ankle joints of the RA group with A1AT antibody 
showed a strong positive signal in synovial joints, and this $46 \mathrm{kDa}$ protein was also detected by western blotting. This study suggests that in a mouse model of rheumatoid arthritis, joint inflammation increases the amount of A1AT in the synovium, and that citrullinated A1AT may be involved in the development of RA.

Next, we examined whether citrullinated anti-CCP anti-bodies or A1AT could also be detected in the salivary glands, but no signal was detected from either antibody when the salivary glands were immunostained. This suggests that the salivary glands themselves do not produce antibodies. This suggests that the salivary glands themselves do not produce antibodies. In other words, citrullination occurred in the synovial membrane of the mouse ankle joint, and the citrullinated protein flowed into the bloodstream, probably into saliva. Since saliva is composed of plasma components, substances in the blood may be detected in saliva. We have reported that PSA, a tumor marker for prostate cancer, is detected in the saliva of mice implanted with prostate tumor and prostate cancer patients in clinical trials, and that there is a correlation between PSA concentrations in blood and saliva of mice and humans [37]. Of note, autoantibodies are not produced in salivary glands, but are thought to be transferred from blood [38], which can be applied clinically in the case of RA. However, as the results of ELISA showed, the amount of antibody detected in saliva is lower than in the serum or ankle joints because the plasma component is diluted when transferred to saliva. This is an issue that must be considered in the practical application of saliva testing for RA, along with the sensitivity of ELISA. However, in this study, anti-CCP antibody was not detected by ELISA in the saliva of the control group, and that the severe RA group showed significantly higher values than the mild RA group. Therefore, the quantification of A1AT protein by ELISA will be an important part of the future detection strategy.

This study had some limitations. The citrullinated A1AT was identified in this study, but carbamylation was not examined. Future studies should focus not only on citrullinated A1AT but also on carbamylated A1AT and conduct multifaceted analyses including pathological tissues. Furthermore, since the present results were obtained in mice, it is necessary to verify the results using human saliva in the future. By comprehensively examining various biomarkers such as anti-CCP antibodies and citrullinated A1AT in saliva, we may be able to establish a method for the early diagnosis of RA.

\section{Materials and Methods}

\subsection{Animals}

Male 12-15-week-old DBA/1JJmsSlc mice (SLC Japan, Shizuoka, Japan) were acquired. The mice were kept in a specific pathogen-free (SPF) room and allowed free access to food and tap water. The mice were divided into three groups: control, mild RA (12week-old DBA mice) and severe RA (15-week-old DBA mice) groups (Table 1). The experimental protocol was approved by the Kanagawa Dental University Animal Experiment Ethics Committee (approval No. 19-013) and the experiment was performed in accordance with the Guidance for Animal Experimentation of Kanagawa Dental University and the ARRIVE Guidelines (Animal Research: Reporting of In Vivo Experiments). Care and use of laboratory animals were also carried out in accordance with the guidelines of the National Institutes of Health (NIH Publications No. 8023, revised 1978).

\subsection{RA induction}

Bovine type II collagen $(0.2 \mathrm{mg})$ was administered at the base and ridge of the auricle (50 $\mu \mathrm{g}$ total collagen/mouse) at weeks 7 and 10 in the RA DBA mice. For the control group, we administered the same amount of saline in the same manner. Sampling was performed at the age of 12 weeks in group 2 and 15 weeks in groups 1 and 3 (Figure 9). The joints of the feet were evaluated by the arthritis index on a 5-point scale. The index was scored as 
0 , no change; 1 , finger swelling; 2 , finger and foot swelling; 3 , whole foot swelling; 4 , and severe swelling. This was based on the same technique as previously reported [30].

Table 1. Antibodies used for immunostaining and western blotting and their dilution factors.

\begin{tabular}{|c|c|c|c|c|c|}
\hline & Antibody & Supplier & $\begin{array}{l}\text { Iso- } \\
\text { type }\end{array}$ & $\begin{array}{l}\text { Dilution } \\
\text { for IHC }\end{array}$ & $\begin{array}{l}\text { Dilution } \\
\text { for WB }\end{array}$ \\
\hline \multirow[t]{2}{*}{$\begin{array}{l}\text { Primary } \\
\text { antibody } \\
\text { for IHC } \\
\text { and WB }\end{array}$} & $\begin{array}{c}\text { CCP polyclo- } \\
\text { nal } \\
\text { antibody } \\
\text { (bs-1053R) }\end{array}$ & $\begin{array}{c}\text { Bioss } \\
\text { (Woburn, MA, } \\
\text { USA) }\end{array}$ & $\operatorname{IgG}$ & $1 / 300$ & $1 / 500$ \\
\hline & $\begin{array}{c}\text { Anti-alpha } 1 \\
\text { antitripsin an- } \\
\text { tibody } \\
\text { (ab231093) }\end{array}$ & $\begin{array}{c}\text { Abcam } \\
\text { (Cambridge, UK) }\end{array}$ & $\operatorname{IgG}$ & $1 / 300$ & $1 / 1000$ \\
\hline $\begin{array}{l}\text { Secondary } \\
\text { antibody } \\
\text { for WB }\end{array}$ & $\begin{array}{c}\text { Histofine } \\
\text { mouse stain kit }\end{array}$ & $\begin{array}{l}\text { Nichirei Biosci- } \\
\text { ence } \\
\text { (Tokyo, Japan) }\end{array}$ & & & \\
\hline $\begin{array}{l}\text { Secondary } \\
\text { antibody } \\
\text { for WB }\end{array}$ & $\begin{array}{l}\text { Polyclonal } \\
\text { goat } \\
\text { anti-rabbit } \\
\text { immuno- } \\
\text { globins HRP }\end{array}$ & $\begin{array}{c}\text { DAKO } \\
\text { (Santa Clara, CA, } \\
\text { USA) }\end{array}$ & $\operatorname{IgG}$ & & $1 / 1000$ \\
\hline $\begin{array}{l}\text { Negative } \\
\text { control for } \\
\text { IHC }\end{array}$ & $\begin{array}{l}\text { Rabbit IgG, } \\
\text { polyclonal- } \\
\text { isotype control } \\
\text { (ab37415) }\end{array}$ & $\begin{array}{c}\text { Abcam } \\
\text { (Cambridge, UK) }\end{array}$ & $\operatorname{IgG}$ & $1 / 300$ & \\
\hline
\end{tabular}

IHC, immunohistochemistry; WB, western blot; $\mathrm{CCP}$, anti-citrullinated peptide;

HRP, horseradish peroxidase

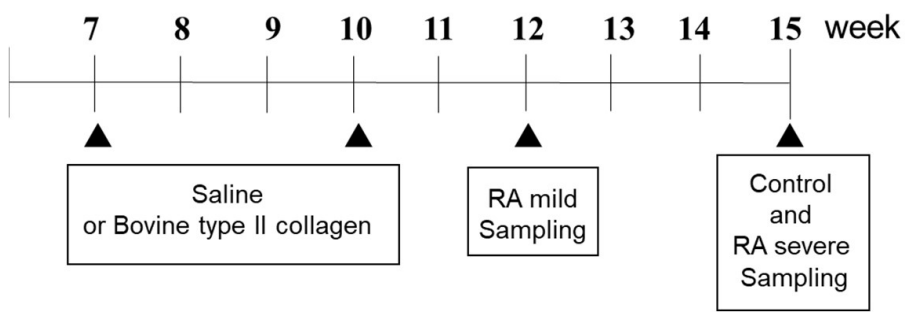

Figure 10. The administration time for bovine type II collagen and sampling time for each group of mice.

\subsection{Sample preparation}

At week $12,1 \mathrm{mg} / \mathrm{kg}$ of the nonselective muscarinic receptor stimulator pilocarpine (Sampiro 1\%, Santen, Osaka, Japan) was administered intraperitoneally to each mouse, 
and saliva was collected using a micropipette. Blood was then collected by cardiac puncture. Serum components were separated in a vacuum blood collection tube (Benoject II, Terumo, Tokyo, Japan) and centrifuged $\left(10,000 \times g, 15\right.$ minutes, $\left.4^{\circ} \mathrm{C}\right)$. Mouse ankle joints were removed and one joint was used as the tissue sample, while the other was used as the bone sample; these were subjected to Cryo-press (Microtec Company Limited, Chiba, Japan) and suspended in 1\% Triton X-100 (MP Biomedicals, Inc.; homogenised with PBS) and stored at $-80^{\circ} \mathrm{C}$.

\subsection{Micro CT evaluation}

Radiological examination was used to assess bone destruction. The amputated mouse ankle joints were frozen and photographed by micro CT, for which a ScanXmateL080 (Comscantechno, Kanagawa, Japan) was used.

\subsection{Histological analysis of the ankle joints}

The ankle joints (proximal part) was fixed in buffered $10 \%$ formalin ( $\mathrm{pH} 7.4$ ) (Fujifilm Wako Pure Chemical Corporation, Osaka, Japan) for $17 \mathrm{~h}$, demineralised with Kalkitox (FujifilmWako Pure Chemical Co) for 21 days, then embedded in paraffin. Paraffin blocks were cut into 5 - $\mu \mathrm{m}$ sections and HE staining was performed. The submandibular gland was similarly fixed with formalin, embedded, sectioned, and stained with HE.

\subsection{Protein identification by LC-MS/MS analysis}

Gel fragment peptides obtained by protease treatment were separated and concentrated by reversed-phase high-performance liquid chromatography (EASY-nLC1200, Thermo Fisher Scientific K.K., Tokyo, Japan) and detected using a mass spectrometer Q Exactive Plus (Thermo Fisher Scientific K.K.). The data were subjected to a database search (Mascot search) to identify the proteins.

\subsection{Immunohistochemical staining}

Immunohistochemical staining was performed on the serial sections of the mouse ankle joints. Information on the antibodies and antigens can be found in Table 1. Paraffin sections were deparaffinized, dehydrated, and reacted with hydrogen peroxide solution for $10 \mathrm{~min}$. Blocking reagent A (Nichirei Bioscience, Tokyo, Japan) was applied at $37^{\circ} \mathrm{C}$ for $1 \mathrm{~h}$, then the primary antibody (Table 1 ) was reacted at $37^{\circ} \mathrm{C}$ for $1 \mathrm{~h}$ and incubated with the sections. Blocking reagent B (Nichirei Bioscience Inc.) and Simple Stain MAX-PO (Nichirei Bioscience Inc.) were each reacted for $10 \mathrm{~min}$ at room temperature. Finally, the cells were permeabilised with Simple Stain Substrate DAB (Fujifilm Wako Pure Chemical Industries Co., Ltd.) for $7 \mathrm{~min}$, stained with Mayer's haematoxylin (Muto Pure Chemical Industries, Ltd., Tokyo, Japan), and sealed. Using the same technique, mouse submandibular glands were also stained. The specificity of the primary antibodies was shown using a negative control. Rabbit IgG was used as the negative control (Abcam).

\subsection{Detection of citrullinated proteins}

CCP concentrations in the mouse serum, saliva, and ankle joint were measured by ELISA, for which a mouse anti-CCP antibody ELISA kit (CUSABIO BIOTECH, CSBEQ027743MO, Wuhan, China) was used. Samples were added to each well (100 $\mu \mathrm{L})$ using a CCP pre-coated plate and incubated at $37^{\circ} \mathrm{C}$ for $2 \mathrm{~h}$. The addition and incubation of biotin conjugates, horseradish peroxidase (HRP)-avidin, and 3,3', 5,5'-tetramethylbenzidine (TMB) substrates were repeated, and the absorbance at $450 \mathrm{~nm}$ was measured using an automated microplate reader (BioRad, Hercules, CA, USA). 


\subsection{Analysis of citrullinated protein}

Each sample (serum and saliva, and ankle joints of the RA and control groups) was loaded into a 15\% polyacrylamide gel (Super SepTMAce; LKN6604, Wako Pure Chemicals). The concentration of each protein was measured beforehand and adjusted to $180 \mu \mathrm{g}$ depending on the amount of sample loaded into the gel. The proteins were electrophoretically separated and electrophoresed onto polyvinylidene fluoride membranes (Immobilon, Merck Millipore, ISEQ10100, Frankfurt, Germany). The membranes were blocked with $5 \%$ skim milk and reacted with CCP primary antibody at $22^{\circ} \mathrm{C}$ overnight then HRP secondary antibody at $22^{\circ} \mathrm{C}$ for $1 \mathrm{~h}$. Image analysis was performed using a CCD camera (LAS3000; Fujifilm, Tokyo, Japan). Information on the antibody and antigen search is shown in Table 1 . The density of each band was examined using an image analyser (ImageJ, version: ij153-win-java8; NIH, Bethesda, MD, USA). This method was adapted from the technique in a previous paper [28].

\subsection{Statistical analysis}

The arthritis scores of the ankle joints were compared using the Wilcoxon signedrank test, because the data were not normally distributed based on the KolmogorovSmirnov test. The CCP antibody levels determined by the ELISA method were compared using Welch's ANOVA followed by post-hoc tests with the Bonferroni correction, because the data followed the normal distribution based on the Kolmogorov-Smirnov test. Statistical significance was set at $p<0.05$. All statistical analyses were performed using IBM Statistics for Windows, version 23.0 (IBM Corp., Armonk, NY, USA).

\section{Conclusions}

The purpose of this study was to comprehensively analyze citrullinated proteins in saliva by proteomics using a mouse model of rheumatoid arthritis and to clarify the etiology of rheumatoid arthritis by histopathological analysis. First, we detected various citrullinated proteins in mouse ankle joints, serum and saliva by proteomics, and identified A1AT commonly in serum and saliva and ankle joints of severe RA model mice. Immunohistochemical staining with anti-CCP and A1AT antibodies showed strong positive signals in the ankle synovium of RA model mice. Western blotting detected anti-CCP antibody and citrullinated A1AT in blood, saliva, and ankles, and the band intensity was stronger in severe RA model mice. A1AT and CCP antibodies were not detected in salivary gland tissue, suggesting that antibodies are not produced in the salivary glands themselves, but in the synovial membrane of the ankle. These results suggest that citrullinated proteins produced in the ankle synovium are transferred to blood and saliva. This suggests that citrullinated A1 AT and CCP antibodies may be involved in the development of rheumatoid arthritis and the severity of arthritis in model mice. These findings extend our current knowledge of rheumatoid arthritis and provide a basis for further research.

Supplementary Materials: The following are available online at www.mdpi.com/xxx/s1, Figure S1: The total length of the gel lane in western blotting analysis; Figure S2: Some of the citrullinated proteins identified by proteome analysis.

Author Contributions: Investigation, W.S., J.S., Y.Y., T.S., M.T., and M.Y.; formal analysis, W.S. and S.F.; writing - original draft preparation, W.S. and J.S.; supervision, K.T. Management and coordination responsibility for the research activity planning and execution. All authors have read and agreed to the published version of the manuscript.

Funding: This research was funded by JSPS KAKENHI Grant-in-Aid for Research Activity Start-up, grant number [19K24107]. 
Institutional Review Board Statement: The experimental protocol used in this study was reviewed and approved by the Ethics Committee for Animal Experiments of KANAGAWA DENTAL UNIVERSITY (approval-number: 19-013, approval-date: 22 July 2019) and was performed in accordance with the Guidelines for Animal Experimentation of KANAGAWA DENTAL UNIVERSITY, and the Animal Research: Reporting of In Vivo Experiments (ARRIVE) guidelines for reporting animal research.

Data Availability State: Data are available upon request from author.

Acknowledgments: We would like to thank the Kanagawa Dental College Graduate School Central Research Centre for their technical support in conducting the experiment. We also would like to thank Antegral (Tokushima, Japan) for their proteome analysis, and Editage (www.editage.com) for English language editing.

Conflicts of Interest: The authors declare no conflict of interest.

\begin{abstract}
Abbreviations
ACPA, anti-citrullinated protein antibody; A1AT, alpha-1-antitrypsin; anti-CCP, antibody anti-cy cliccitrullinated peptide antibody, anti-CarP antibodies, anti-carbamylated protein antibodies Anx7, annexin 7; BDNF, brain-derived neurotrophic factor; DMARDs, disease-modifying antirheumatic drugs; ELISA, enzyme linked immunosorbent assay; HE, haematoxylin and eosin; Micro CT micro computed tomography; NETs, neutrophil extracellular traps; PAD, peptidylarginine deiminase; $P$. gingivalis, Porphyromonas gingivalis; RA, rheumatoid arthritis; SF, synovial fluid;

SPF, specific pathogen-free; ARRIVE, Animal Research Reporting of In Vivo Experiments Guidelines
\end{abstract}

\title{
References
}

1. van der Woude, D.; van der Helm-van Mil, A.H.M. Update on the epidemiology, risk factors, and disease outcomes of rheumatoid arthritis. Best Pract. Res. Clin. Rheumatol. 2018, 32, 174-187; DOI: 10.1016/j.berh.2018.10.005.

2. Joosten, L.A.; Lubberts, E.; Helsen, M.M.; Saxne, T.; Coenen-de Roo, C.J.; Heinegård, D.; van den Berg, W.B. Protection against cartilage and bone destruction by systemic interleukin-4 treatment in established murine type II collagen-induced arthritis. Arthritis. Res. 1999, 1, 81-91; DOI: 10.1186/ar14.

3. Klareskog, L.; Stolt, P.; Lundberg, K.; Källberg, H.; Bengtsson, C.; Grunewald, J.; Rönnelid, J.; Harris, H.E.; Ulfgren, A.K.; Rantapää-Dahlqvist, S.; Eklund, A.; Padyukov, L.; Alfredsson, L. A new model for an etiology of rheumatoid arthritis: smoking may trigger HLA-DR (shared epitope)-restricted immune reactions to autoantigens modified by citrullination. Arthritis. Rheum. 2006, 54, 38-46; DOI: 10.1002/art.21575.

4. Padyukov, L.; Silva, C.; Stolt, P.; Alfredsson, L.; Klareskog, L. A gene-environment interaction between smoking and shared epitope genes in HLA-DR provides a high risk of seropositive rheumatoid arthritis. Arthritis. Rheum. 2004, 50, 3085-3092; DOI: 10.1002/art.20553.

5. Germain, V.; Scherlinger, M.; Barnetche, T.; Pichon, C.; Balageas, A.; Lequen, L.; Shipley, E.; Foret, J.; Dublanc, S.; Capuron, L.; Schaeverbeke, T.; Hospitalo-Universitaire, ACRONIM. F. Role of stress in the development of rheumatoid arthritis: a casecontrol study. Rheumatology (Oxford) 2020, 60, 629-637; DOI: 10.1093/rheumatology/keaa216.

6. Klareskog, L.; Stol, P.; Lundberg, K.; Källberg, H.; Bengtsson, C.; Grunewald, J.; Rönnelid, J.; Harris, H.E.; Ulfgren, A.K.; Rantapää-Dahlqvist, S.; Eklund, A.; Padyukov, L.; Alfredsson, L. Oxidative stress relevance in the pathogenesis of the rheumatoid arthritis: a systematic review. Biomed. Res. Int. 2016, 2016, 6097417; DOI: 10.1155/2016/6097417.

7. Hashimoto, H.; Yamazaki, T.; Hamaguchi, M.; Morimoto, T.; Yamori, M.; Asai, K.; Isobe, Y.; Furu, M.; Ito, H.; Fujii, T.; Terao, C.; Mori, M.; Matsuo, T.; Yoshitomi, H.; Yamamoto, K.; Yamamoto, W.; Bessho, K.; Mimori, T. Periodontitis and Porphyromonas gingivalis in preclinical stage of arthritis patients. PLoS One 2015, 10, e0122121; DOI: 10.1371/journal.pone.0122121.

8. Cheng, Z.; Meade, J.; Mankia, K.; Emery, P.; Devine, D.A. Periodontal disease and periodontal bacteria as triggers for rheumatoid arthritis. Best Pract. Res. Clin. Rheumatol. 2017, 31, 19-30; DOI: 10.1016/j.berh.2017.08.001.

9. Badsha, H. Role of diet in influencing rheumatoid arthritis disease activity. Open Rheumatol. J. 2018, 12, 19-28; DOI: 10.1016/j.berh.2017.08.001.

10. Kishikawa, T.; Maeda. Y.; Nii, T.; Motooka, D.; Matsumoto, Y.; Matsushita, M.; Matsuoka, H.; Yoshimura, M.; Kawada, S.; Teshigawara, S.; Oguro, E.; Okita, Y.; Kawamoto, K.; Higa, S.; Hirano, T.; Narazaki, M.; Ogata, A.; Saeki, Y.; Nakamura, S.; Inohara, H.; Kumanogoh, A.; Takeda, K.; Okada, Y. Metagenome-wide association study of gut microbiome revealed novel 
aetiology of rheumatoid arthritis in the Japanese population. Ann. Rheum. Dis. 2020, 79, 103-111; DOI: 10.1136/annrheumdis2019-215743.

11. Wang, W.; H. Zhou.; Liu, L. Side effects of methotrexate therapy for rheumatoid arthritis: A systematic review. Eur. J. Med. Chem. 2018, 158, 502-516; DOI: 10.1016/j.ejmech.2018.09.027.

12. Roubille, C.; Haraoui, B. Interstitial lung diseases induced or exacerbated by DMARDS and biologic agents in rheumatoid arthritis: a systematic literature review. Semin. Arthritis Rheum. 2014, 43, 613-626; DOI: 10.1016/j.semarthrit.2013.09.005.

13. Masson-Bessière, C.; Sebbag, M.; Girbal-Neuhauser, E.; Nogueira, L.; Vincent, C.; Senshu T.; Serre, G. The major synovial targets of the rheumatoid arthritis-specific antifilaggrin autoantibodies are deiminated forms of the alpha- and beta-chains of fibrin. J. Immunol. 2001, 166, 4177-4184; DOI: 10.4049/jimmunol.166.6.4177.

14. Vossenaar, E.R; Després, N.; Lapointe, E.; van der Heijden, A.; Lora, M.; Senshu, T.; van Venrooij, W.J.; Ménard, H. A.; Rheumatoid arthritis specific anti-Sa antibodies target citrullinated vimentin. Arthritis Res. Ther. 2004, 6, R142-R150; DOI: 10.1186/ar1149.

15. Suzuki, A.; Yamada, R.; Yamanaka, M.O.; Okazaki, Y.; Sawada, T.; Yamamoto, K. Anti-citrullinated collagen type I antibody is a target of autoimmunity in rheumatoid arthritis. Biochem. Biophys. Res. Commun. 2005, 333, 418-426; DOI: 10.1016/j.bbrc.2005.05.137.

16. Oda, T.; Yoshie, H.; Yamazaki, K. Porphyromonas gingivalis antigen preferentially stimulates T cells to express IL-17 but not receptor activator of NF-kappaB ligand in vitro. Oral Microbiol. Immunol. 2003, 18, 30-36; DOI: 10.1034/j.1399302x.2003.180105.x.

17. Ridgley, L.A.; Anderson, A.E.; Maney, N.J.; Naamane, N.; Skelton, A. J.; Lawson, C. A.; Emery, P.; Isaacs, J.D.; Ruaidhrí J Carmody, R.J.; Pratt, A.G. IL-6 mediated transcriptional programming of naïve CD4+ T Cells in early rheumatoid arthritis drives dysregulated effector function. Front. Immunol. 2019, 3, 1535; DOI: 10.3389/fimmu.2019.01535.

18. Aslam, B.; Basit, M.; Atif Nisar, M. A.; Khurshid, M.; Rasool, M. H. Proteomics: technologies and their applications. J. Chromatogr. Sci. 2017, 55, 182-196; DOI: 10.1093/chromsci/bmw167.

19. Iizuka, N.; Okamoto, K.; Matsushita, R.; Kimura, M.; Nagai, K.; Arito, M.; Kurokawa, M.S.; Masuko, K.; Suematsu, N.; Hirohata, S.; Kato, T.; Identification of autoantigens specific for systemic lupus erythematosus with central nervous system involvement. Lupus 2010, 19, 717-726; DOI: 10.1177/0961203309357764.

20. Bohnenberger, H.; Kaderali, L.; Ströbel, P.; Yepes, D.; Plessmann, U.; Dharia, N.V.; Yao, S.; Heydt, C.; Merkelbach-Bruse, S.; Emmert, A.; Hoffmann, J.; Bodemeyer, J.; Reuter-Jessen, K.; Lois, A.M.; Dröge, L.H.; Baumeister, P.; Walz, C.; Biggemann, L.; Walter, R.; Häupl, B.; Comoglio, F.; Pan, K.T.; Scheich, S.; Lenz, C.; Küffer, S.; Bremmer, F.; Kitz, J.; Sitte, M.; Beißbarth, T.; Hinterthaner, M.; Sebastian, M.; Lotz, J.; Schildhaus, H.U.; Wolff, H.; Danner, B.C.; Brandts, C.; Büttner, R.; Canis, M.; Stegmaier, K.; Serve, H.; Urlaub, H.; Oellerich, T. Comparative proteomics reveals a diagnostic signature for pulmonary head-andneck cancer metastasis. EMBO Mol. Med. 2018, 10; DOI: 10.15252/emmm.201708428.

21. Kamada, T.; Kurokawa, M.S.; Kato, T.; Takenouchi, K.; Takahashi, K.; Yoshioka, T.; Uchida, T.; Mitsui, H.; Suematsu, N.; Okamoto, K.; Kazuo Yudo, K.; Yasuo Katayama, Y.; Nakamura, H. Proteomic analysis of bone marrow-adherent cells in rheumatoid arthritis and osteoarthritis. Int. J. Rheum. Dis. 2012, 15, 169-178; DOI: 10.1111/j.1756-185X.2012.01702.x.

22. Mun, S.; Lee, J.; Park, A.; Kim, H.J.; Lee, Y.J.; Son, H.; Shin, M.; Lim, M.K.; Kang, H.G. Proteomics approach for the discovery of rheumatoid arthritis biomarkers using mass spectrometry. Int. J. Mol. Sci. 2019, 20, 4368; DOI: 10.3390/ijms20184368.

23. Matsuo, K.; Arito, M.; Noyori, K.; Nakamura, H.; Kurokawa, M.S.; Masuko, K.; Okamoto, K.; Nagai, K.; Suematsu, N.; Yudoh, K.; Beppu, M.; Saito, T.; Kato, T. Arthritogenicity of annexin VII revealed by phosphoproteomics of rheumatoid synoviocytes. Ann. Rheum. Dis. 2011, 70, 1489-1495; DOI: 10.1136/ard.2010.145524.

24. Ballinger, M.L.; Goode, D.L.; Ray-Coquard, I.; James, P.A.; Mitchell, G.; Niedermayr, E.; Puri, A.; Schiffman, J.D.; Dite, G.S.; Cipponi, A.; Maki, R.G.; Brohl, A.S.; Myklebost, O.; Stratford, E.W.; Lorenz, S.; Ahn, S.M.; Ahn, J.H.; Kim, J.E.; Shanley, S.; Beshay, V.; Randall, R.L.; Judson, I.; Seddon, B.; Campbell, I.G.; Young, M.A.; Sarin, R.; Blay, J.Y.; O'Donoghue, S.I.; Thomas, D.M. Monogenic and polygenic determinants of sarcoma risk: an international genetic study. Lancet Oncol. 2016, 17, 12611271; DOI: 10.1016/S1470-2045(16)30147-4.

25. Qian, K.; Wang, Y.; Hua, L.; Chen, A.; Zhang, Y. New method of lung cancer detection by saliva test using surface-enhanced Raman spectroscopy. Thorac. Cancer 2018, 9, 1556-1561; DOI: 10.1111/1759-7714.12837.

26. François, M.; Bull, C.F.; Fenech, M.F.; Leifert, W.R. Current state of saliva biomarkers for aging and Alzheimer's disease. Curr. Alzheimer Res. 2019, 16, 56-66; DOI: 10.2174/1567205015666181022094924.

27. Cohen, M.; Khalaila, R. Saliva $\mathrm{pH}$ as a biomarker of exam stress and a predictor of exam performance. J. Psychosom. Res. 2014, 77, 420-425; DOI: 10.1016/j.jpsychores.2014.07.003.

28. Sakaguchi, W.; Kubota, N.; Shimizu, T.; Saruta, J.; Fuchida, S.; Kawata, A.; Yamamoto, Y.; Sugimoto, M.; Yakeishi, M.; Tsuki noki, K. Existence of SARS-CoV-2 entry molecules in the oral cavity. Int. J. Mol. Sci. 2020, 21, 6000; DOI: 10.3390/ijms21176000. Ben-Assa, N.; Naddaf, R.; Gefen, T.; Capucha, T.; Hajjo, H.; Mandelbaum, N.; Elbaum, L.; Rogov, P.; King, D.A.; Kaplan, S.; Rotem, A.; Chowers, M.; Szwarcwort-Cohen, M.; Paul, M.; Geva-Zatorsky, N. Direct on-the-spot detection of SARS-CoV-2 in patients. Exp. Biol. Med. (Maywood) 2020, 245, 1187-1193; DOI: 10.1177/1535370220941819. 
30. Sakaguchi, W.; To, M.; Yamamoto, Y.; Inaba, K.; Yakeishi, M.; Saruta, J.; Fuchida, S.; Hamada, N.; Tsukinoki, K. Detection of anti-citrullinated protein antibody (ACPA) in saliva for rheumatoid arthritis using DBA mice infected with Porphyromonas gingivalis. Arch. Oral Biol. 2019, 108, 104510; DOI: 10.1016/j.archoralbio.2019.104510.

31. Shi, J.; Knevel, R.; Suwannalai, P.; van der Linden, M.P.; Janssen, G.M.; van Veelen, P.A.; Levarht, N.E.; van der Helm-van Mil, A.H.; Cerami, A.; Huizinga, T.W.; Toes, R.E.; Trouw, L.A. Autoantibodies recognizing carbamylated proteins are present in sera of patients with rheumatoid arthritis and predict joint damage. Proc. Natl. Acad. Sci. U S A 2011, 108, 17372-17377; DOI: 10.1073/pnas.1114465108.

32. Verheul, M.K.; Yee, A.; Seaman, A.; Janssen, G.M.; van Veelen, P.A.; Drijfhout, J.W.; Toes, R.E.M.; Mahler, M.; Trouw, L.A. Identification of carbamylated alpha 1 anti-trypsin (A1AT) as an antigenic target of anti-CarP antibodies in patients with rheumatoid arthritis. J. Autoimmun. 2017, 80, 77-84; DOI: 10.1016/j.jaut.2017.02.008.

33. Janciauskiene, S.; Welte, T. Well-known and less well-known functions of alpha-1 antitrypsin. Its role in chronic obstructive pulmonary disease and other disease developments. Ann. Am. Thorac. Soc. 2016, 13 Suppl 4, S280-S288; DOI: 10.1513/AnnalsATS.201507-468KV.

34. Ferrarotti, I.; Ottaviani, S.; Silvestri, A. D.; Angelo G Corsico, A. G. Update on $\alpha$ 1-antitrypsin deficiency. Breathe (Sheff) 2018, 14, e17-e24; DOI: 10.1183/20734735.015018.

35. Oguntuyo, K.Y.; Stevens, C.S.; Siddiquey, M.N.; Schilke, R.M.; Woolard, M.D.; Zhang, H.; Acklin, J.A.; Ikegame, S.; Hung, C.T.; Lim, J.K.; Cross, R.W.; Geisbert, T.W.; Ivanov, S.S.; Kamil, J.P.; Lee, B. In plain sight: the role of alpha-1-antitrypsin in COVID 19 pathogenesis and therapeutics. bioRxiv 2020, DOI: 10.1101/2020.08.14.248880.

36. de Loyola, M.B.; Dos Reis, T.T.A.; de Oliveira, G.X.L.M.; da Fonseca Palmeira, J.; Argañaraz, G.A.; Argañaraz, E.R. Alpha-1antitrypsin: A possible host protective factor against Covid-19. Rev. Med. Virol. 2021, 31, e2157; DOI: 10.1002/rmv.2157.

37. Shiiki, N.; Tokuyama, S.; Sato, C.; Kondo, Y.; Saruta, J.; Mori, Y.; Shiiki, K.; Miyoshi, Y.; Tsukinoki, K. Association between salivaPSA and serum PSA in conditions with prostate adenocarcinoma. Biomarkers 2011, 16, 498-503; DOI: 10.3109/1354750X.2011.598566.

38. Sakihara, S.; Kageyama, K.; Oki, Y.; Doi, M.; Iwasaki, Y.; Takayasu, S.; Moriyama, T.; Terui, K.; Nigawara, T.; Hirata, Y.; Hash imoto, K.; Suda. T. Evaluation of plasma, salivary, and urinary cortisol levels for diagnosis of Cushing's syndrome. Endocr. J. 2010, 57, 331-337; DOI: 10.1507/endocr.k09e-340. 